\title{
Erratum to: P2X7R blockade prevents NLRP3 inflammasome activation and brain injury in a rat model of intracerebral hemorrhage: involvement of peroxynitrite
}

\author{
Liang Feng ${ }^{1}$, Yizhao Chen ${ }^{1 *}$, Rui Ding ${ }^{2}$, Zhenghao Fu ${ }^{3}$, Shuo Yang ${ }^{4}$, Xinqing Deng ${ }^{5}$ and Jun Zeng ${ }^{1}$
}

\section{Erratum}

After publication of this work [1], it was noted that there was an error within Figs. 6 and 8: both these figures were inadvertently transposed with one another. This has been correctly updated in the original article, and is also included correctly below.

\begin{abstract}
Author details
${ }^{1}$ The National Key Clinical Specialty, The Engineering Technology Research Center of Education Ministry of China, Guangdong Provincial Key Laboratory on Brain Function Repair and Regeneration, Department of Neurosurgery, Zhujiang Hospital, Southern Medical University, Guangzhou 510282, China. ${ }^{2}$ Department of Neurosurgery, Jingmen No. 1 People's Hospital, Jingmen, Hubei 448000, China. ${ }^{3}$ Department of Neurosurgery, The Fifth Affiliated Hospital of Southern Medical University, Guangzhou 510900, China. ${ }^{4}$ Department of Neurosurgery, Gaoqing Campus of Central Hospital of Zibo, Gaoqing People's Hospital, Gaoging, Zibo, Shandong 256300, China. ${ }^{5}$ Department of Neurosurgery, 999 Brain Hospital, Jinan University, Guangzhou, Guangdong 510510, China.
\end{abstract}

Received: 14 June 2016 Accepted: 14 June 2016

Published online: 17 August 2016

\section{Reference}

1. Feng $L$, Chen Y, Ding R, Fu Z, Yang S, Deng X, et al. P2X7R blockade prevents NLRP3 inflammasome activation and brain injury in a rat model of intracerebral hemorrhage: involvement of peroxynitrite. J Neuroinflammation. 2015:12:190. doi:10.1186/s12974-015-0409-2.

* Correspondence: yizhao chen@hotmail.com

'The National Key Clinical Specialty, The Engineering Technology Research Center of Education Ministry of China, Guangdong Provincial Key Laboratory on Brain Function Repair and Regeneration, Department of Neurosurgery, Zhujiang Hospital, Southern Medical University, Guangzhou 510282, China Full list of author information is available at the end of the article
Submit your next manuscript to BioMed Central and we will help you at every step:

- We accept pre-submission inquiries

- Our selector tool helps you to find the most relevant journal

- We provide round the clock customer support

- Convenient online submission

- Thorough peer review

- Inclusion in PubMed and all major indexing services

- Maximum visibility for your research

Submit your manuscript at www.biomedcentral.com/submit 


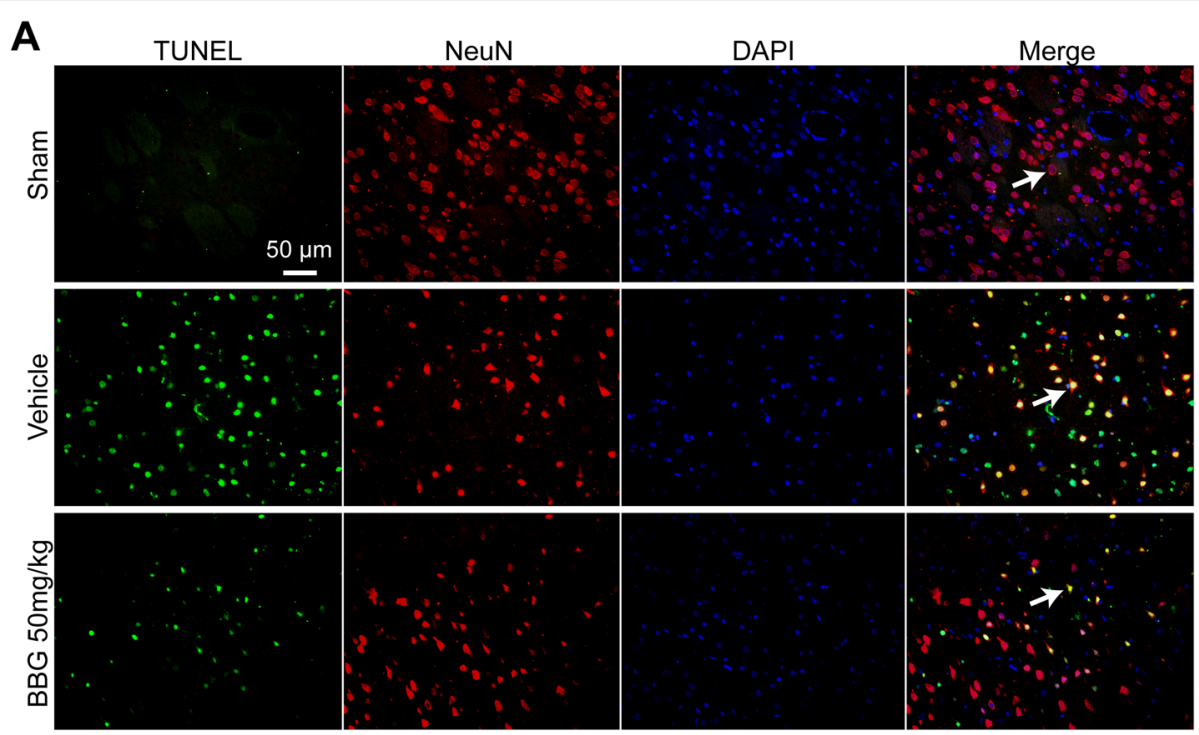

B
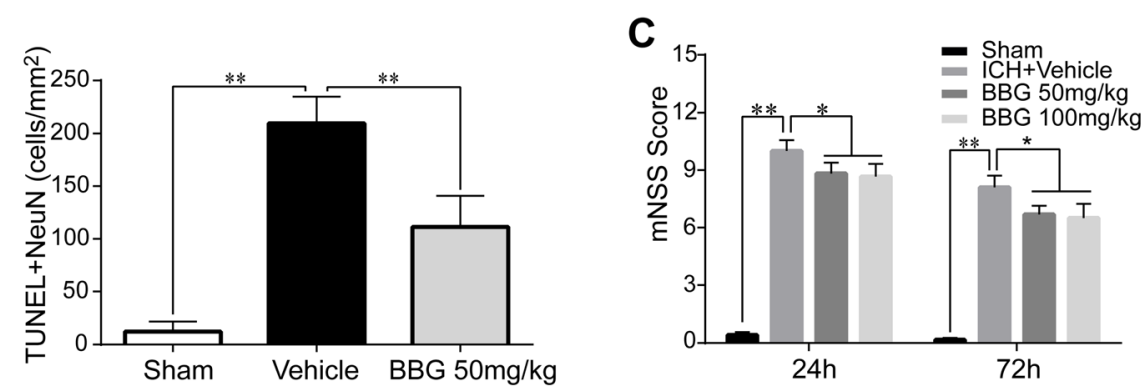

Fig. 6 Effects of BBG on neuronal apoptosis and neurological outcomes in ICH rats. BBG significantly reduced the number of apoptotic neurons (a, b) $24 \mathrm{~h}$ following $\mathrm{ICH}, \mathrm{n}=6$ rats per group. BBG significantly improved neurological deficits (c) at 24 and at $72 \mathrm{~h}$ after ICH, $\mathrm{n}=6$ rats per group. Scale bar $=50 \mu \mathrm{m}$. Data represent means $\pm S D$. ${ }^{*} P<0.05,{ }^{* *} P<0.01$. BBG brilliant blue $G$

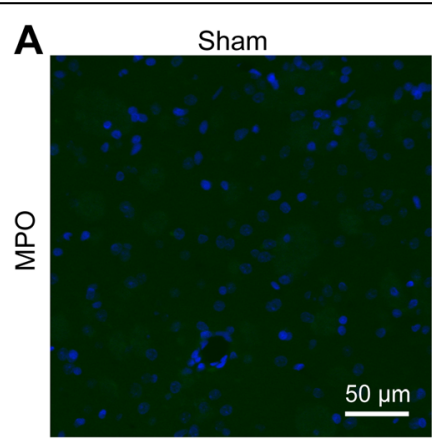

B

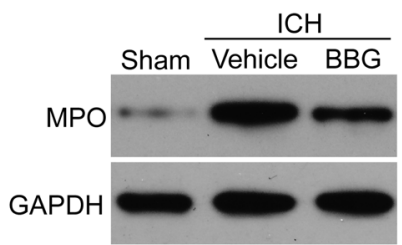

$\mathrm{ICH}+$ Vehicle

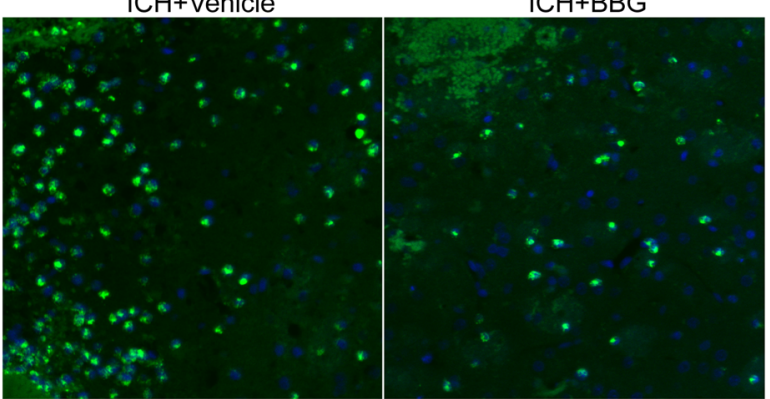

C

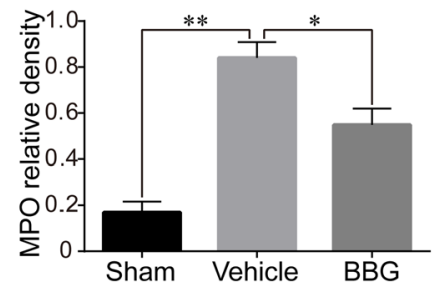

Fig. 8 Effects of BBG on neutrophils infiltration after ICH. Representative photographs of immunofluorescence staining (a) for MPO (neutrophil marker)-positive cells in perihematomal area in the Sham, Vehicle, and BBG $(50 \mathrm{mg} / \mathrm{kg})$ groups at $24 \mathrm{~h}$ following operation, $\mathrm{n}=6 \mathrm{rats}$ per group. Representative western blot (b) and effects of BBG on MPO levels (c) at $24 \mathrm{~h}$ after $\mathrm{ICH}, \mathrm{n}=4$ rats per group. Scale bar $=50 \mu \mathrm{m}$. Data represent means $\pm S D$. * $P<0.05$, * $P<0.01$. BBG brilliant blue G, ICH intracerebral haemorrhage 